\title{
Repair Practice in the Classroom Conversations of Indonesian EFL Students
}

\author{
Madar Aleksius \\ Universitas Katolik Widya Mandira \\ Correspondence concerning this article should be addressed to Madar Aleksius, Universitas Katolik Widya \\ Mandira, English Education Study Program, Jalan San Juan, Penfui Timur, Kupang NTT, 85361, Indonesia. \\ E-mail: madaraleksius@unwira.ac.id
}

\begin{abstract}
This study examines repair practice by English as a Foreign Language (EFL) college students to address the understanding problems that may cause communication breakdowns in classroom conversations. Conversational data were elicited from 40 second-semester students performing jigsaw and information gap communicative tasks. Using the conversation analysis theory and methodological approach, the recorded and transcribed conversations were analyzed to scrutinize the frequency and types of repair strategies, trouble sources, and repair outcomes. The findings show that to address the understanding problem, the EFL college students employed 11 otherinitiated repair strategies: Open-class or unspecified strategies; WH-interrogatives; Partial repeat plus WH- interrogatives; Repetition or partial repetition; Candidate understanding; Correction; Request for repetition; Non-verbal; Asking for definition, explanation, translation, example, or spelling; Explicit display of non-understanding; and Request to speak up. These other-initiated repair strategies were triggered by the presence of lexical, semantic contentrelated, and sequential/speech delivery trouble sources.Attempts to resolve the understanding problem were conducted by a set of repair outcomes, including Repetition, Acknowledgment, Repetition or acknowledgment plus expansion, explanation, and/or translation, and Repetition or acknowledgment plus translation.The study provides language educators with new insights on how EFL learners deal with understanding problems in communication so that they could respond appropriately to the repair practice initiated by the students.
\end{abstract}

Keywords: conversation analysis, repair practice, other-initiated repair, trouble source, repair outcome, EFL student, classroom conversations

\section{Introduction}

Repair practice as a joint interactional accomplishment between conversational interlocutors (Barraja-Rohan, 2011) used to avoid communication problems is one of the important components of communicative competence (Canale \& Swain, 1980; Celce-Murcia, 2007).In conversation analysis (henceforth CA), repair means "addressing trouble appearing in interactive language use" (Seedhouse, 2005, p.168) such as "in speaking, hearing, or understanding of talk"(Wong \& Waring, 2010, p.212).Furthermore, Schegloff (2000, p.207) asserted that not all forms of understanding problems are addressed by repair practice, but are limited only to the understanding of an utterance that has been just said by the previous speaker.

According to Gardner (2013), studying repair in classroom interactions from a CA perspective is only about a decade in age, and that what people have done so far is only "scratching the surface" (p.610).While some studies (Bae \& Oh, 2013; Bolden, 2012) on classroom repair have shown the similarities and differences with ordinary interactions, there is still a need to find out different types of repair in classroom conversations and how the learners change from a lower level to a higher level through the repair process (Gardner, 2013).The current study, then, attempted to scrutinize other-initiated repair (henceforth OIR) as one of the strategies that EFL students use to address the understanding problem in their classroom conversations using the CA angle.This is a common phenomenon that many EFL learners still face when encountering problems in their interactions with their peers or with native speakers of English due to their lack of ability to deploy necessary repair strategies to address such understanding problems. Studying this phenomenon would add to our understanding of how learning a foreign language occurs as learners' endeavor to achieve shared understanding during their interactions. 
The application of CA in applied linguistics and language learning has been flourishing, especially after the publication of Seedhouse's, (2005) state-of-the-art article on the connection of CA with the learning of a language and Kasper \& Wagner's (2014) publication about the application of CA in applied linguistics. Various studies have been conducted to examine language learning and classroom interactions by employing the CA approach (Azkarai \& Agirre, 2016; Bae \& Oh, 2013; Cancino, 2015; Cancino, 2020; Hellermann \& Lee, 2014; O'Neal, 2015; Radford, 2010; Ryan, 2015) These studies used naturally occurring conversational data between English non-native speakers and English native speakers. The studies by Bae and Oh (2013) andHellermann and Lee (2014)reconceptualizedthe concepts of native and non-native speakers and language ability as language learners' identities. Both studies see language learners' as non-native speakers or deficient language users as something that sequentially evolves through the interaction process.Through their practice of using OIR, language learners are enacting their identities as non-native speakers.

Other researchers, such as Cancino's (2015) study with young language learners and Azkarai and Agirre's (2016) study with upper-intermediate proficiency learners, investigated whether age, proficiency level, and setting influenced the practice of addressing understanding problems in the interactions of EFL learners. Similar to ESL learners, EFL learners negotiate for meaning during L2 task-based interactions and employ a variety of strategies that help them in the task completion process and when attempting to solve understanding problems during their interactions with peers and teachers.Learning opportunities through classroom interactions are heightened or hindered depending upon the teacher's proper understanding and utilization of how the interaction unfolds moment-by-moment in regard tolearners' turns and utterances based on a particular context of their occurrence (Cancino, 2015)

OIR practice is operated through the use of different types of strategies, such as an Open-class (Drew, 1997) OIR, a strategy used with no specification of trouble source in the turn prior to the OIR strategy, when the problem is related to hearing, misunderstanding of talk, or both (Wong \& Waring, 2010).Studies on this strategy include Dehé (2015) in Icelandic,Enfield et al., (2013) in mundane conversations across several languages,Fotovatnia and Dorri (2013) in Iranian EFL learners conversations, Golato and Golato (2015) in German and French, and Hayashi and Kim (2015) in Japanese and Korean. These studies found that the Openclass OIR strategy is represented by the interrogative pronoun 'what' or an interjection 'huh' or "yeah", which are used either in isolation or in combination with other OIR types, such as repetition, to address different kinds of trouble sources.

Another strategy, Repetition, is used by repeating some parts of the trouble source turn for repair initiation, usually delivered with a rising intonation to convey uncertainty and to "invite the speaker of the trouble-source to complete the repair" (Wong \& Waring, 2010, p. 232).Kaur (2012) found that repetition is used to exhibit an expression of astonishment, disbelief, or nonalignment, and to heighten the recipient's understanding by making the expression clearer.Other studies ( Lilja, 2014; Osvaldsson, Persson-Thunqvist \& Cromdal, 2013; Persson, 2015; Rabab'ah, 2013; Wang \& Wu, 2015) found that in addressing the understanding problems, repetition functions to treat the recognized problems of comprehension, to treat a specific language-related understanding problem, to request to repeat and to ask for confirmation, and to facilitate the learners in identifying the trouble source in their utterances.

The next common type of OIR strategy is a Correction, either an exposed or embedded correction (Wong \& Waring, 2010).Correction strategy has been reported to be have been performed by teachers and the students to address language-related trouble sources, such as with adjectives, vocabulary, and grammar (Åhlund \& Aronsson, 2015; Lee, 2013; Osvaldsson, Persson-Thunqvist, \& Cromdal, 2013 ).In a study with high-level graduate students in an EFL setting, Lee (2013) revealed that exposed correction is a corrective feedback strategy that the students most prefer to use in both their teacher-student and peer interaction.These studies drew important conclusions about the learning initiative taken by the learners in addressing communication problems due to the existence of non-target constructions in peer interaction, and not merely the responsibility of the teacher.

Code-switching, "an alternating use between two languages" (Tavakoli, 2012, p. 61), is also commonly used as a repair strategy, especially in an EFL setting.In their investigations of Japanese/English bilingual interaction practice, Greer (2013) and Sasuga and Greer (2014) found that code-switching is employed to indicate that an interlocutor is having a problem searching for a word(s) to continue his/her utterance.By switching codes, the 
speaker signals a problem of how to continue the utterance, thus, seeking assistance from the other speaker in the interaction.Repair and code-switching are also used by learners as crucial interactional resources to cooperate in language learning and to build a rapport (Lehti-Eklund, 2013; Tudini, 2016).

The next type of OIR strategy is Candidate understanding, i.e. an interactional strategy used when someone repeats an utterance from the previous turn with different words to show his/her understanding of the utterance. Candidate understanding is used not only to disclose one's understanding of the previous speaker's turn but also functions as an offer of help in formulating utterances in a more understandable way (Kushida, 2011).Benjamin (2012) suggested that this strategy is commonly used as an OIR in various conversational settings to repair understanding problems occurring in the turn that adjoins the turn where it appears in the conversation.

One way to signal an understanding problem in face-to-face interactions is by using Non-verbal signs, such as gestures or other visual practices(Gardner, 2013).Investigations on this practice have been done by several researchers such as Seo and Koshik (2010), Sert and Jacknick (2015), Floyd, Manrique, Rossi, and Torreira (2016), Mortensen (2016),Hömke, Holler, and Levinson (2017), and Walker (2017). It was found that certain types of gestures such as head turns are understood to be a way of initiating a repair and function in the same way as an Open-class OIR such as "huh?”.Furthermore, eye blinking as a kind of non-verbal behavior was found to be limited to a certain context, and that it is used to signal understanding or non-understanding of the current speaker’s utterance (Hömke, Holler, \& Levinson, 2017).

The use of different types of OIRs is mainly triggered by the existence of trouble sources in the turns before the OIR turn. Such trouble sources cause an understanding problem for the OIR speaker that encourages the interlocutors to take steps to solve it.Trouble sources can take different forms, for example due to unclear lexical meaning (Saldert, Ferm, \& Bloch,2014), pronunciation problems (O’Neal, 2015; Plug, 2015), or pragmatic, lexical, morphological, phonological elements (Morgenstern, Leroy-Collombel, \& Caët, 2013).In addition to the problems related to language use, OIRs may also be employed due to a speech delivery problem in the previous speaker's turn.A study by Hoey (2015) specifically investigated the occurrence of lapses that may become a source of the interactional problem because, during this silent period, it is not known who is going to speak next or what to do next.

Based on the above review of the studies, it can be ascertained that the employment of other-initiated repair is basically to address an understanding problem that occurs ubiquitously in different communication settings, such as in mundane/ordinary interactions as well as institutional settings.Those studies inform us that it is ordinary that communication breakdowns take place because of misunderstandings on either side of the conversation.Since CA is "a systematic study of talk produced in everyday situations of human interactions" (Hutchby \& Wooffitt, 2002, p.13), most of the conversational data presented in the studies are taken from ordinary or mundane interaction involving native speakers of a particular language.However, although still limited in number, there have been some attempts to implement CA methodology for analyzing interactions between the non-native speaker (NNS) and native speaker (NS), either in a classroom setting or in an ordinary setting (for example Khodadady \& Alifathabadi, 2012;Lázaro-Ibarrola \& Azpilicueta-Martínez, 2015). Therefore, more studies need to be conducted on the enactment of different types of OIR strategies in conversations involving NNSs, such as EFL learners. The current study is an attempt to fill this gap and proposes the following research question to be investigated in this study: How do EFL college students enact OIR practice in classroom conversations? Specifically, what are the types of OIR strategies, trouble sources, and repair outcomes that occur in their conversations?

\section{Materials and Methods}

\section{Participants and Data Collection}

The participants of the current study consisted of a group of EFL students who enrolled in an English Education Study Program at Widya Mandira Catholic University, a small private university located in Timor, an island in the eastern part of Indonesia.The total number was forty students $(\mathrm{m}=17 ; \mathrm{f}=23)$, ranging in age between $18-20$ years.As a part of their undergraduate teacher training, the students have to program some speaking subjects 
that aim at developing their speaking ability as candidate English teachers.During the data collection of the current study, the students were enrolled in the Speaking for Everyday Conversation subject, the first of a series of speaking subjects they need to take during their four-year teacher training program. Thus, the data were elicited from the intact class of Speaking for Everyday Conversation. It was purposively chosen by the lecturer who taught the subject because the students were in their initial stage of learning English and their level of proficiency was rated low-intermediate, so that the chance for them to negotiate meaning and perform repair initiation was high.

The conversational data were obtained when the students worked in pairs on jigsaw and information gap communicative language tasks.In the Jigsaw task, each member of a pair had to find and understand the information from another member ofanother pair so that it could be described to the homegroup clearly.In the Information Gap task, the students engaged in a so-called split information activity (Nation \& Newton, 2009) where they worked in pairs to complete the task by sharing information needed by their interlocutors. The main characteristic of the split information task was that the learners could only find the required answers by working together and exchanging information verbally. Therefore, they were expected to engage in an active conversational exchange without looking at the picture of their interlocutor.

The students' conversations were audio- and video-recorded to obtain both the verbal features and the nonverbal behaviors of the conversations.The recording started when the students opened the conversations and ended when they were closed. Overall, there were 52 sets of conversations produced by the students, 34 from the jigsaw task and 18 from the information gap task.The students' conversations were then transcribed in detail using the transcription model proposed by ten Have (2007) which is simplified from that of Atkinson and Heritage (1999), a general transcription convention commonly employed in conversation analytic studies.The transcription model was chosen because it provides a accurate representation not only of the vocal representation of talks but also the non-vocal symbols, such as gaze, gestures, and laughter/smile.

The transcription represented four main features of conversational data.First, sequencing represents the way that conversational turns are ordered in relation to other speaker's previous or next turn.Second, time intervals represent the occurrence of silences between turns or within a turn. Third, the characteristics of speech production represent the way a speaker utters the words or sentences in his/her turns.Fourth, transcriber's doubts or comments represent comments given for unclear speech by the speakers.

\section{Data Analysis}

The unit of analysis focused on conversational instances where the OIR trajectories appeared by examining the sequences of conversational turns.As the guideline for determining the OIR trajectory, the anatomy of OIR by Enfield et al. (2013) was followed, as shown in the following diagram.

\section{Figure 1}

Trajectory of Other-Initiated Repair

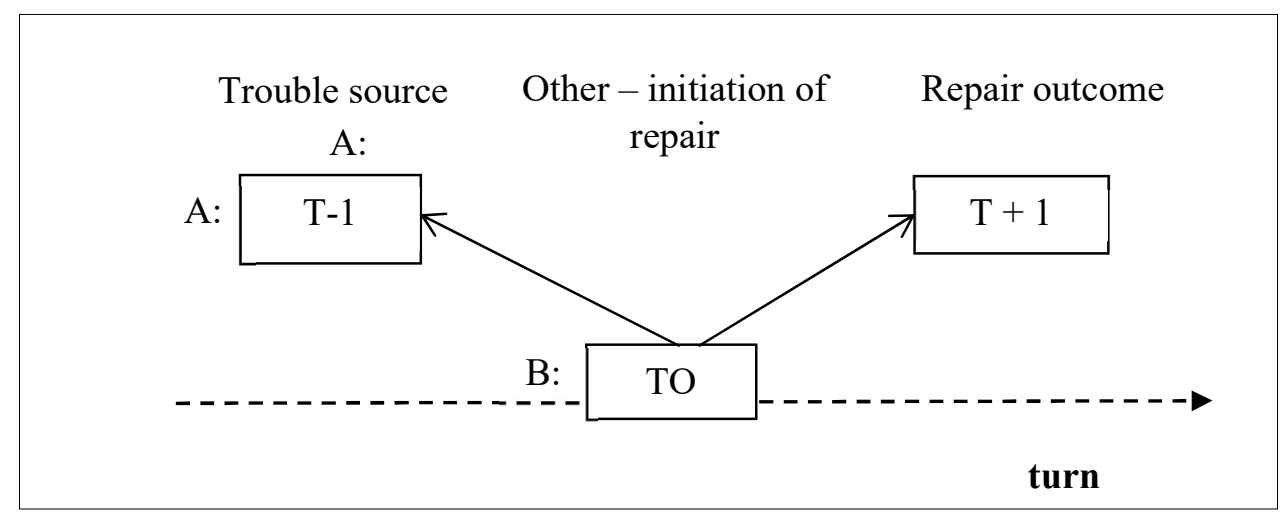


TO means the turn where the OIR strategy occurs that points back to a problem source in Turn -1 and points forward to a next turn, Turn +1 , where the problem is repaired as the result of the OIR strategy use.The basis for the determination of types of OIR strategies came from the works ofSchegloff, Jefferson, and Sacks (1977) and Wong and Waring (2010), which were employed as guidelines while the actual occurrence depended on whether or not the participants employed them in their conversations.

- Open-class or unspecified OIR. It is used without specifying a trouble source in the turn before the OIR strategy, whether is related to hearing, misunderstanding of talk, or both.It is indicated by the use of Huh?, What? Pardon? I'm sorry? Excuse me?

- WH-Interrogative OIR. Using a question like "who", "where", or "when" as repair initiation that specifies the trouble source of the prior turn.

- Repeating part of the trouble source plus a WH-interrogative OIR. A question word is used together with the repetition of the trouble source turn.

- Repetition or partially repeating of the trouble-source OIR. Some parts of the trouble source are repeated in repair initiation, usually delivered in a rising intonation, to convey uncertainty so the producer of the trouble source enacts a repair.

- Candidate understanding OIR. It involves an understanding check often preceded by You mean. It is done by targeting more specifically the trouble in the previous speaker's turn.

- Correction repair strategy OIR. It refers to stopping the trajectory of talks to overtly address a trouble source.

- Request for repetition OIR.The repair initiator explicitly asks the previous speaker to repeat the utterance that might have caused the understanding problem.

- Non-verbal repair strategy. Use of body language and silence to indicate that one is having a problem understanding the utterance of the previous speaker.

The categories of trouble source types in this research were based on the findings of previous studies by Morgenstern, Leroy-Collombel, and Caët (2013), Saldert, Ferm, and Bloch (2014), O’Neal (2015), Plug (2015), and Hoey (2015 and 2017).The studies indicated that the trouble sources can take different types, including lexical meaning trouble sources, pronunciation trouble sources, grammar trouble sources, semantic content in the utterances, and speech delivery, such as lapses, overlapping, and cut-off speech.When examining the data, however, the types of trouble sources were not limited to the ones mentioned above but opened to any new types that appeared in the data.The repair outcome comes after a T-O turn and is produced by the speaker of the trouble source in T-1. Depending on their occurrence in conversational data, repair outcome categories can take different forms, such as repetition, explanation,corrections, and acknowledgment.

\section{Results}

Based on the results of data elicitation, recordings, and transcription, the analysis found that the students managed to produce 52 sets of conversations, from which 370 sets of OIR trajectories were excerpted.The OIR trajectories were examined by using the guidelines proposed by Enfield, et al. (2013, p.346) above.Then, the types of OIR strategies, trouble sources, and repair outcomes in every trajectory were identified.

\section{Types and Frequency of OIR Strategies in the EFL Students' Conversations}

Table 1 presents the frequency distribution of each OIR type.

\section{Table 1}

\begin{tabular}{clcc}
\multicolumn{1}{c}{ Types and frequencies of OIR strategies } & \multicolumn{1}{c}{ Type } & f & $\%$ \\
\hline No & & 72 & 19.45 \\
1 & Open-class or unspecified strategy & 34 & 9.20 \\
2 & WH-interrogatives OIR & 15 & 4.05
\end{tabular}




\begin{tabular}{|c|c|c|c|}
\hline No & Type & $\mathbf{f}$ & $\%$ \\
\hline 4 & Repetition or partial repetition & 91 & 24.60 \\
\hline 5 & Candidate understanding & 22 & 5.94 \\
\hline 6 & Correction & 19 & 5.14 \\
\hline 7 & Request for repetition & 64 & 17.30 \\
\hline 8 & Non-verbal & 13 & 3.52 \\
\hline 9 & Asking for definition/ explanation/ translation/ example/ or spelling & 28 & 7.56 \\
\hline 10 & Explicit displayof non-understanding & 6 & 1.62 \\
\hline \multirow[t]{2}{*}{11} & Request to speak up & 6 & 1.62 \\
\hline & & 370 & 100 \\
\hline
\end{tabular}

All the categories of OIR types proposed by Schegloff, Jefferson, and Sacks (1977) and Wong andWaring (2010) occurred in the students' conversations. However, after analyzing the data, new categories were found, namely (1) asking for a definition/ explanation/ example/ translation/ or spelling; (2) explicit display of nonunderstanding; and (3) request to speak up.Although these three OIR types occupied the lowest three positions in frequency of occurrence, their presence indicated that the EFL students in the current study had particular strategies to deal with the understanding problems in their conversations. Repetition or partial repetition that occurred seemed to be the most favorable strategy followed by an Open-class or unspecified strategy.

To understand better how these OIR strategies are enacted in the students' conversations,examples taken from the conversation excerpts are provided below.All names that appeared in the conversation excerpts are pseudonames.

Excerpt 1. Conversation 1/Hadi and Elen/Jigsaw_Home: Repetition/partial repetition OIR strategy

\begin{tabular}{llll}
\hline 9. & Hadi & : & I want to tell you about uh:: traditional ceremony from Pakalia's uh:: hometown in Soe (1.0) \\
10. & Elen & $:$ & the traditional name is uh:: Baukneno \\
11. & Hadi & $:$ & Baukneno? \\
12. & Elen & $:$ & yes $=$ \\
13. & & I think the same with me $(\mathrm{hhhh})$ \\
\hline
\end{tabular}

Excerpt 1 exemplifies the Repetition OIR strategy where Elen initiated repair in line 11 by repeating the word "Baukneno" from her interlocutor's turn in line 10.It seems that Elen had to make sure that she heard the word correctly because it was a new word for her. Hadi's response in line 12 indicates that the problem was resolved.

Excerpt 2. Conversation 32/Beth and Ando/Jigsaw_Home: Open-class or unspecified OIR strategy

\begin{tabular}{llll}
\hline 17. & Beth & $:$ & uh:: I like- I don’t like the Justin Bieber an::d \\
18. & Ando $\rightarrow$ & and what the::: favorite music about Justin Bieber do you hear \\
19. & Beth & $:$ & yes? \\
20. & Ando & $:$ & what the:: TITLE I mean the title of the song \\
\hline
\end{tabular}

In Excerpt 2, an Open-class/unspecified OIR strategy was employed by Beth in line 19. Beth seemed not to understand Ando's utterance in line 18 "and what the::: favorite music about Justin Bieber do you hear", so she initiated a repair by saying "yes?"There was no specific part(s) of Ando's utterance that caused her understanding problem.Ando response in line 20 resolved her problem that what he meant was the title of a Justin Bieber song.

Excerpt 3. Conversation 52/Ferdi and Lara/Information Gap: Candidate understanding OIR strategy

\begin{tabular}{llll}
\hline 60. & Ferdi & $:$ & sorry sorry I am not- okay if you feel saying this thing okay (4.0) yes it's the same as mine \\
61. & Lara & $:$ & picture number eight is yours number eight this thing is different part of the leg for to the toes \\
62. & Ferdi & $:$ & that pants that body \\
63. & Lara & $:$ & you mean it to make pants narrow or wide? \\
64. & Ferdi & & uh:: \\
65. & & you mean it to make pants narrow or wide? \\
66. &
\end{tabular}


The Candidate understanding OIR strategy is exemplified in Excerpt 3.In line 63, Lara seemed to have a problem understanding Ferdi's utterance in line 62, so she tried to offer her understanding by saying "you mean it to make pants narrow or wide?" However, Ferdi could not explain the utterance, so Lara repeated her question in line 65.It showed that the sequence did not result in resolving the understanding problem as Ferdi did not give any clarification to Lara's offer of understanding in her next turn. Such an unsuccessful resolution of the understanding problem was quite common in these EFL students' conversations.

Excerpt 4. Conversation 26/Pask and Niki/Jigsaw_Home: Correction OIR strategy

\begin{tabular}{llll}
\hline 120. & Pask & $:$ & district in my district there are many:: (1.0) tourism place \\
121. & Niki & $:$ & tourism places? \\
122. & Pask & $:$ & tourism places $(2.0)$ and uh:: every $(2.0)$ every people $(2.0)$ came $(1.0)$ around the world come- \\
123. & & & came around the world to visit our my my district uh:: there are uh:: $(2.0)$ \\
124. & &
\end{tabular}

Excerpt 4 is an example of a grammatical correction OIR strategy. Line 120 of Pask's turn contained a grammatical mistake ".......many tourism place", so Niki took an initiative to repair it in line 121 by providing a correct form "many places". The correction was accepted by Pask in line 122 by repeating the correct form, then continuing with his utterance.

Excerpt 5. Conversation 23/Beth and Paul/Jigsaw_Home: Non-verbal OIR strategy

\begin{tabular}{llll}
\hline 13. & Beth & $:$ & yes he's bring a camera when he was doing photoshop \\
14. & Paul & $:$ & oh good all right uh:: (3.0) uh:: (2.0) did he (2.0) get something for take a picture (frowning) \\
15. & Beth & $:$ & maksudnya dia dapat uang dari ambil foto “I mean whether he gets any money from taking a \\
16. & Paul & $:$ & picture" did he get something for take a picture \\
17. & Beth & $:$ & yes he getsand now can you tell me about Marsi \\
18. & & &
\end{tabular}

Excerpt 5 exemplifies the employment of facial expressions as a Non-verbal OIR strategy.In line 15, Beth frowned to indicate that she did not understand Paul's utterance in line 14. It was then repaired by Paul in line 16 by using translation and repetition strategies on the trouble sources that appeared in line 13.Beth's understanding problem was resolved as seen by her positive response in line18.

Excerpt 6. Conversation 51/Ferdi and Lara/Information Gap: Explicit display of non-understanding OIR strategy

\begin{tabular}{llll}
\hline 50. & Lara & $:$ & uh:: mouth bird mouth bird uh:: (2.0) it is (function) to the store food and the (lock) usually is \\
51. & Ferdi & $:$ & it in the dark and the picture \\
52. & Lara & $:$ & sorry I don't catch what you mean \\
53. & Ferdi & $:$ & it is (function) to the story storm \\
54. & & & storm?
\end{tabular}

Excerpt 6 shows the employment of the Explicit display of non-understanding strategy.Ferdi (line 52) seemed not to have any idea about Lara's utterance in line 50-51 because it contained some ill-formed construction such as "bird mouth", "is it in the dark and the picture", unclear speech delivery like "(function)","(lock)", and an intra-turn pause of 2.0 seconds.Ferdi expressed his understanding problem by saying "sorry I don't catch what you mean", hoping that Lara would explain herself better or more clearly, which was to no avail.She even produced another trouble source "storm" which triggered Ferdi to initiate the Repetition OIR strategy. Thus, the repair initiation sequence was not successful in overcoming the understanding problem.

\section{Types and Frequency of Trouble Sourcesin the Students' Conversations}

Table 2 presents the trouble sources that occurred in the students' conversations. 
Table 2

Types and frequencies of trouble sources

\begin{tabular}{llcc}
\hline \multicolumn{1}{c}{ Type } & f & \% \\
\hline & Lexical trouble sources & 205 & 55.40 \\
& Semantic content-related trouble sources & 102 & 27.57 \\
& Sequential/Speech delivery & 63 & 17.03 \\
& Total & $\mathbf{3 7 0}$ & $\mathbf{1 0 0}$ \\
\hline
\end{tabular}

As shown in Table 3, there were three types of trouble sources identified in the students' conversations. They were lexical, semantic content-related, and sequential/speech delivery trouble sources.Lexical trouble sources covered lexical meaning, pronunciation, and grammar.Semantic content trouble sources meant the overall unclear message in the T-1 utterance.Sequential trouble sources are related to the smoothness of speech production due to the presence of lapses, pauses, cut-off speech, or loudness of speech.

Most of the lexical trouble sources were related to proper nouns such as names of places or objects and common nouns that were either unfamiliar to the students or considered as a new word.Others were associated with pronunciation or grammatical problems.Excerpt 7 below demonstrates an example of a proper name as a trouble source. It showed that the name "Atambuku" in Elen's turn in line 42 was unfamiliar for Rina, so she initiated a repair in line 43 by repeating the trouble source "Atambuku".Then in line 44, Elen ascertained that the name she meant was really "Atambuku" as a lake.

Excerpt 7. Conversation 9/Elen and Rina /Jigsaw_Home:Proper name as Lexical Trouble Source

\begin{tabular}{llll}
\hline 40. & Elen & $:$ & $\begin{array}{l}\text { and the- uh:: Kofainufamuri lake is the same color with Atapolo lake the same colour (2.0) yes } \\
\text { the same color they are so red colour yes (4.0) and the last one is Atambuku lake }\end{array}$ \\
41. & Rina & Atambuku? \\
42. & Elen & $\begin{array}{l}\text { yes Atambuku lake. an::d Atambuku lake is:: (2.0) I think there so:::: like chokol- chocolate } \\
\text { (hhh) }\end{array}$ \\
43. & & \\
45. & &
\end{tabular}

The following excerpt exemplifies mispronunciation as a trouble source.In line 52, Tini mispronounced the word "chain" as [kain] and it triggered Beth to employ the OIR strategy in line 53 by saying "huh?". Tini continued to mispronounce the word in line 54 but, then, it was repaired by Beth in line 55 with the correct pronunciation.

Excerpt 8. Conversation 46/Beth and Tini /Information Gap: Mispronunciation as Lexical Trouble Source

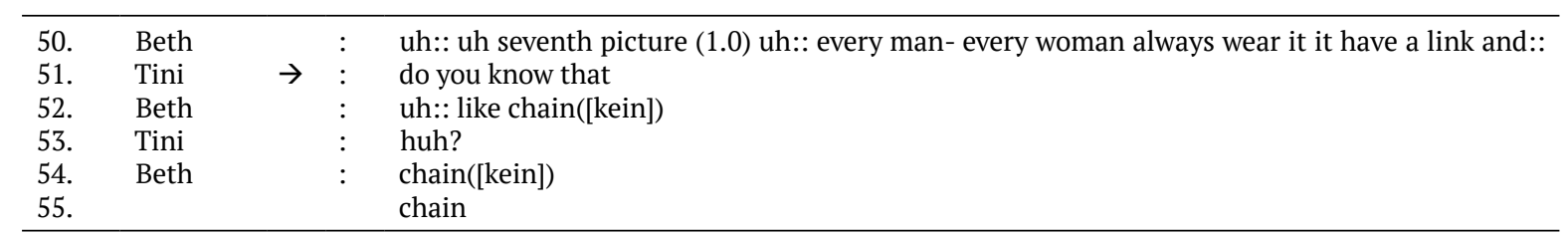

The next excerpt is an example of a semantic content-related trouble source which contained an utterance with unclear meaning or message that prompted the employment of OIR strategy.It can be seen in Excerpt 9 that Gabi seemed to have a problem understanding Kari's utterance in lines 19 and 20 so he initiated a repair strategy in line 21 . To deal with this problem, Kari offered a translation in line 22 and it helped Gabi continue his speaking turn in line 23.

Excerpt 9. Conversation 31/Gabi and Kari /Jigsaw_Home: Semantic content-related trouble source

\begin{tabular}{llll}
\hline 19. Kari & : & I like type musical is uh:: (2.0) keyboard and guitar (2.0) and what do you kind to::: football \\
20. & Gabi & $:$ & huh? \\
21. & Kari & $:$ & apa yang kamu suka dari “what do you like from” football \\
22. & Gabi & $:$ & because $(2.0)$ because football is sport \\
23. & & & \\
\hline
\end{tabular}


The following excerpt displays an example of a sequential/speech delivery trouble source that caused misunderstanding in the students' conversations.

Excerpt 10. Conversation 43/Nela and Yuli/Information Gap: Sequential/Speech Delivery rouble source

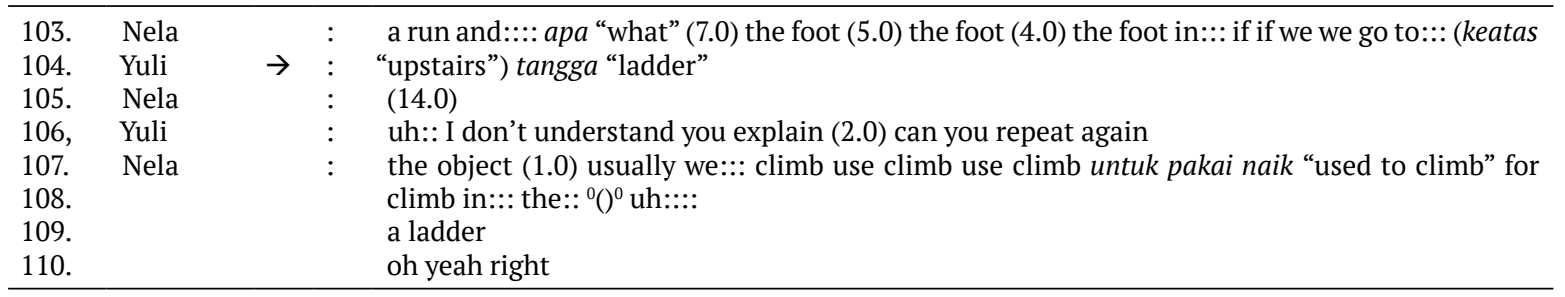

As displayed, Nela's turn in lines 103 and 104 contained several long pauses, sound prolongation (indicated by the semicolons), and even unclear speech production that triggered the employment of an OIR strategy by Yuli in line 106.Nela attempted to refine her turn in lines 107 and 108 and that seemed to help Yuli guess the item she was explaining before.

\section{Types and Frequency of Repair Outcomes in the Students' Conversations}

From the analysis of the students' conversations, it was found that there are seven categories of repair outcomes that were distinctive to these particular EFL students. Table 3 below presents the repair outcomes.

\section{Table 3}

Types and frequencies of repair outcomes

\begin{tabular}{llll}
\hline No & \multicolumn{1}{c}{ Type } & f & \% \\
\hline & Repetition & 184 & 49.73 \\
Acknowledgment & 38 & 10.27 \\
Repetition or acknowledgment plus expansion & 51 & 13.78 \\
Explanation & 23 & 6.22 \\
Translation & 18 & 4.86 \\
Repetition or acknowledgement plus translation & 20 & 5.41 \\
Not successful & 36 & 9.73 \\
Total & $\mathbf{3 7 0}$ & $\mathbf{1 0 0}$ \\
\hline
\end{tabular}

As shown in Table 3, Repetition seemed to be the most dominant repair outcome employed by the students.In this case, the interlocutor just repeated the lexical items that might have triggered the understanding problem in the conversation.In some other cases, the students did not only repeat the problematic item but also expanded it with additional information such as an acknowledgement or explanation.Translation, either appearing by itself or in combination with other strategies such as Repetition or Acknowledgement, inescapably occurred in these EFL students' conversations given the fact that they came from the same L1 background.

Excerpt 11 exemplified the employment of Repetition combined with an expansion as a repair outcome strategy in the students' conversation.

Excerpt 11. Conversation 2/Rina and Alia/Jigsaw_Home: Repetition plus expansion repair outcome

\begin{tabular}{|c|c|c|c|c|}
\hline 63. & Rina & & : & Kelimutu lake (1.0) is very very beautiful place and I think you know you know the place \\
\hline 64. & Alia & $\rightarrow$ & : & I know \\
\hline 65. & Rina & & : & Kelimutu have (1.0) three color \\
\hline 66. & Alia & & : & three colors? \\
\hline $\begin{array}{l}67 . \\
68 . \\
69 . \\
70\end{array}$ & Rina & & : & $\begin{array}{l}\text { three colors yes and the first uh:: the first the first the first name the first name (2.0) is one } \\
\text { lake the meaning of the :: (1.0) the lake is one one lake is Atapolo lake and (1.0) and Atapolo } \\
\text { lake have blue color. you know? }\end{array}$ \\
\hline
\end{tabular}


In line 68, Rina repeated the trouble source that appeared in her utterance in line 66 after Alia offered a correction OIR in line 67.Furthermore, she supplied more information about "three colors" (the number of colors of Kelimutu lake) to help Alia understand better what she meant by "three colors".

In some cases, the OIR initiation did not yield a successful completion in solving the understanding problem because the speaker of the trouble source did not provide the required response to the repair initiation offered by the initiator of the OIR.In Excerpt 12 below, Pask offered a correction OIR "you didn't go" in line 102 to repair Niki's incorrect grammar in line 101.However, in line 103, Niki did not show whether she accepted the offer because she just continued her turn to talk about something new.

Excerpt 12. Conversation 26/Niki and Pask/Jigsaw_Home: Not-successful repair outcome

\begin{tabular}{llll}
\hline 100. & Niki & $:$ & yes they are uh:: (1.0) especially my:: uh:: sister and my brother $(2.0)$ they very happy because \\
101. & Pask & uh:: (2.0) a long time I don't go back//in village// \\
102. & Niki & $:$ & $\begin{array}{l}\text { //you didn't go // you didn't go } \\
\text { my village and she::: they are very happy because I have uh:: chance to }=\end{array}$ \\
103. & &
\end{tabular}

One of the distinct characteristics of the repair outcome strategy in the students' conversations was the employment of Translation strategy whereby they simply translated the trouble source item into Indonesian to overcome the understanding problem.In Excerpt 13 below, Maia seemed to have a problem with the word "regency" so she initiated a repetition OIR in line 16.To overcome Maia's problem, Arno simply translated the word "regency" into Indonesian in line 17 by saying "kabupaten". The translation was accepted by Maia in line 18 , thus resolving her understanding problem.

Excerpt 13. Conversation 3/Maia and Arno/Jigsaw_Home: Translationrepair outcome

\begin{tabular}{llll}
\hline 14. & Maia & $:$ & I only know Manggarai I don’t know(2.0) East Manggarai West Manggarai \\
15. & Arno $\rightarrow$ & $:$ & it is like $(2.0)$ the regency \\
16. & Maia & $:$ & regency? \\
17. & Arno & $:$ & Kabupaten “regency” \\
18. & Maia & $:$ & oh \\
\hline
\end{tabular}

\section{Discussion}

The study shows that EFL students in Indonesia managed to employ eleven OIR strategies to deal with understanding problems during classroom conversations.The OIR strategies in the current study are different from the ones in Schegloff, Jefferson, and Sacks (1977) and Wong and Waring (2010) who proposed eight OIR types: Open-class or unspecified, WH-interrogative, Partly repeating the trouble source plus WH-interrogative, (Partial) repetition of the problem, Candidate understanding, Correction repair strategy,Request for repetition, and Non-verbal repair strategy. While all those categories appeared in the EFL learners' conversations in the current study, new categories of OIR types also emerged.The new categories were Asking for definition/ explanation/ translation/ example/ or spelling; Explicit display of non-understanding; and Request to speak up.The higher frequency of OIR strategies in these EFL students' conversations indicated that they may have more problems understanding during the course of a conversation due to their limited proficiency in English as language learners.However, it should be acknowledged that although the students were at the beginning level, they managed to employ the OIR strategies to deal with such understanding problems in classroom conversations.

The employment of Repetition or partial repetition strategies to understand new lexical items or grammatical items in the current study is aligned with Kaur's (2014) and Lilja's (2014) studies, which reported that by employing repetition strategies the students are seeking more explanation from the speaker on the trouble sources to clarify the problematic item.Regardless of the students' language proficiency, the language learners' repetition OIRs to overcome the understanding problem of vocabulary item could be due to their lack of linguistic knowledge.The finding of the employment of request of repetition in the learner-learner conversations bears some similarities to other previous studies such as Persson (2015) and Wang and Wu (2015) who noted the employment of repetition functions to treat specific language-related problems such us lexical grammatical problems. 
The Open-class or unspecified strategy was employed when the students had a problem understanding the message in the previous speaker's utterance, although it was not clear which part of the utterance became the source of non-understanding.This finding mirrors the results of various studies on the employment Open-class OIR in ordinary conversations (Dehé, 2015; Drew, 1997;Enfield et al., 2013; Hayashi \& Kim, 2015; Golato \& Golato, 2015)Similar to the current study, these studies found that the uses of the interjection "huh" or question word "what" as Open-class OIRs in different languages are ways to address misunderstandings due to problems in hearing the talk.The use of the interrogative pronoun "what" also appeared as a WH-interrogative OIR strategy that the students employed to target specific trouble sources related to the unfamiliar proper names of places, mispronounced words, unclear speech delivery, or L1 words.The employment of WH-interrogatives as an OIR strategy in the current study showed a similar result in other EFL contexts, such as in Iran ( Emrani \& Hooshmand, 2019; Fotovatnia \& Dorri, 2013) where it is employed to indicate a hearing problem or general understanding of specific trouble sources, such as lexical items, appearing in the prior speaker's utterance.The question words "what", "who", and "when" were used, and the students also used the Partial repeat plus WHinterrogatives OIR strategy to repair trouble sources related to lexical items, such as the unfamiliar proper names of places or mispronunciation of words.By employing these strategies, the students managed to avoid possible breakdowns in the production and understandability of their conversations (Schegloff, 2007).

Another OIR type found was Asking for a definition, explanation, translation, example, or spelling to address a problem of understanding lexical items produced by the interlocutors.Comparably, this finding is incongruent with Liebscher and Dailey-O'Cain's(2003) study on the classroom interactions between a teachers and their students.It was found that both the teacher and the students used requests for definition, translation, or explanation, in an identical way but for different functions.The students used this strategy as a true request for a particular or specific kind of information, such as a problematic lexical item, similar to the practice of the participants of the current study. The recent study by Aleksius et al., (2021) found that this type of OIR strategy was also employed by learners when they engaged in a task-based activity as a technique to assess their speaking ability.

Candidate understanding was one of the OIR strategies performed by the students, usually by using phrases like "you mean ...", "do you mean..." followed by an utterance representing their understanding of the previous speakers' intended meaning.The use of this strategy helped the previous speakers find a way to simplify or clarify what he or she meant so that misunderstanding could be avoided. This finding supports the previous study by Kushida (2011) on the employment of candidate understanding in mundane conversations, which suggested that candidate understanding is a common strategy in various conversational settings to repair understanding problems occurring in the turn that adjoins the turn where it appears in the conversation.EFL learners also need to learn this strategy because, by restating the ideas of the previous speaker, they can avoid misunderstandings and it also enables them to ask for clarification without displaying their non-understanding directly.

The students' conversations also featured the presence of the Correction OIR strategy to repair an incorrect construction in the previous speaker's utterances.The incorrect construction included linguistic errors, such as pronunciation, grammar, morphology, or unclear meaning of words. The presence of such errors is inevitable because the students were in the process of learning the language.Besides, during the data collection, there was no intervention at all regarding the grammaticality or correctness of language use in their speaking.The students were given a free opportunity to talk based on their current language level.This finding is in line with the study of Khodaday and Alifathabadi (2014) with EFL intermediate learners in Iran.The Correction OIR took place in three or more turns and this reveals that the learning initiative could be taken by the learners when addressing communication problems due to the existence of non-target constructions, and it is not merely the responsibility of the teacher.

Another result in the current study was the employment of laughter/smile as a Non-verbal OIR strategy. Laughing was treated as a non-verbal repair initiation because it was employed as an interactional resource, and not just as a response to something humorous.It is an indication that a speaker was having an understanding problem with the previous speaker's utterance.In line with Walker's (2017) study on the usage of laughter by young children in ordinary conversations, the participants of the current study used laughter because they were not able to provide a full verbal answer due to their limited proficiency in English or they might not be willing to do so.The finding also supports Sert and Jacknick (2015) regarding ESL classroom interactions between the teacher and the students.They discovered that smile (as a form of laughter) played a key role in 
resolving interactional troubles due to the students' status as the unknowing participants in the process of knowledge negotiation with their teacher.

In terms of the trouble sources occurring in the students' conversations, it was found that there were three types of trouble sources, namely lexical trouble sources, semantic content trouble sources, and sequential/ speech delivery trouble sources.Lexical trouble sources cover lexical meaning, pronunciation, and grammar. Semantic content trouble sources mean the overall unclear message in the T-1 utterance that was not understandable for the interlocutors.Sequential trouble sources are related to the smoothness of speech production due to the presence of lapses, pauses, cut-off speech, or loudness of speech.Since the participants had a low level of English proficiency, it might be quite normal when their utterances were characterized by the occurrence of such deficient language construction and influent speech delivery, which in this study are treated as interactional resources to build up a turn sequence in the language learning process.This finding supports previous studies (Morgenstern, Leroy-Collombel, \& Caët, 2013; O’Neal, 2015; Plug, 2015) on the different types of linguistic-related trouble sources occurring in mundane conversations.Regarding the sequential/speech delivery trouble sources, the current study is incongruent with Hoey's $(2015,2017)$ studies on British and American English conversations in various conversation settings.The studies found that the trouble sources were treated by the participants by completing the interactional sequence using various OIR strategies such as repetition, candidate understanding, and correction.

Regarding the repair outcomes, it was found that the students in this study managed to employ seven types of repair outcome strategies, namely Repetition; Acknowledgment; Repetition or acknowledgment plus expansion, explanation, and/or translation; Repetition or acknowledgment plus translation; and Not-successful repair outcome.Repetition, Acknowledgment, and Translation (either in isolation or in combination with other repair outcome strategies) were considered linguistically simple and less demanding repair outcome types because most of the time these were expressed as a single-word item or the response token of "yeah" or "yes".The choice of these simple repair outcome strategies might be affected by the students' low-level language proficiency. It also resonates with Schegloff's (1992) claim that the choice of different repair outcome strategies is a typical mechanism in an OIR sequence in all conversation settings regardless of the speakers' language proficiency. The occurrence of Not-successfulrepair outcomes happened because the speaker of the trouble source did not provide the necessary or required response to the speaker of the repair initiation turn, resulting in an incomplete sequence of OIR trajectories.Most of the Not-successful repair outcome cases occurred in the form of silence, i.e. the speaker of the trouble source did not say anything to respond to the repair initiation and it prompted the speaker of the repair initiation to reiterate the repair initiation or to just continue to talk about something new.Kitzinger (2013) confirmed that the failure to respond to the repair initiation is a dispreferred environment in an OIR trajectory because the speaker of the trouble source turn does not use the opportunity to examine his/her turn to find out the cause of misunderstanding problem for the speaker of the repair initiation turn.In the current study, such inability may be explained by the students' lack of ability to develop a connected conversation due to their limited proficiency in English or due to the lack of practice conversing in English.

\section{Conclusion}

The current study shows that in addressing understanding problems in classroom conversations, EFL college students in Indonesia managed to employ a set of OIR strategies and these OIR strategies were triggered by the occurrence of a number of trouble sources.For solving the understanding problems in their conversations, the students employed various types of repair outcomes, some of which were successful, others not. This finding provides language educators with a better understanding of the process of how EFL learners deal with understanding problems during classroom interactions.Therefore, teachers should raise their awareness about different types of conversational problems that occur in the classroom and how their students use repair strategies to overcome such problems. Also, by knowing students' methods for addressing understanding problems in classroom conversations, teachers could systematically prepare their teaching materials and design the speaking classes to incorporate these strategies so that the students' interactional ability to avoid communication problems could develop gradually.

This study, however, has some limitations in terms of the small number of subjects and the specificity of the context from which the data were gathered.The data were taken from freshmen in an undergraduate English 
Study Program at a small private university in Timor, Indonesia.The small number of participants and the specific context make the generalization of the study limited.Therefore future studies with more participants in other settings such as high schools or other university students in Indonesia need to be undertaken to expand the horizon of students' repair practices in the EFL context.Furthermore, since the current study focuses only on the employment of OIR practice between EFL students in classroom conversations, future studies need to be conducted on the conversations between the teacher and students or the students' conversations outside the classroom in order to encompass a better picture of OIR practice in EFL settings.

\section{Acknowledgment}

I would like to thank YAPENKAR (St. Arnoldus Catholic Education Foundation) for partly supporting this research.

\section{References}

Åhlund, A., \& Aronsson, K. (2015). Corrections as multiparty accomplishment in L2 classroom conversations. Linguistics and Education, 30, 66-80. https://doi.org/10.1016/j.linged.2015.03.007

Aleksius, M., Widiati, U., Suharmanto, \& Prayogo, J. A. (2021). Task-Based Assessment in using other-initiated repair strategies of the pre-service EFL teachers. International Journal of Instruction, 14(1), 761-778. https:// doi.org/10.29333/iji.2021.14146a

Atkinson, J. M., \& Heritage, J. (1999). Transcript notation: Structures of social action. Studies in conversation analysis. Aphasiology, 13(4/5), 243-249. https://doi.org/10.1080/026870399402073

Azkarai, A., \& Agirre, I. A. (2016). Negotiation of meaning strategies in child EFL mainstream and CLIL settings. TESOL Quarterly, 50(4), 844-870. https://doi.org/10.1002/tesq.249

Bae, E. Y., \& Oh, S. Y. (2013). Native speaker and nonnative speaker identities in repair practices of English conversation. Australian Review of Applied Linguistics, 36(1), 20-51. https://doi.org/10.1075/aral.36.1.02bae

Barraja-Rohan, A. M. (2011). Using conversation analysis in the second language classroom to teach interactional competence. Language Teaching Research, 15(4), 479-507. https://doi.org/10.1177/1362168811412878

Benjamin, T. (2012). When problems pass us by: Using "you mean" to help locate the source of trouble. Research on Language and Social Interaction, 45(1), 82-109. https://doi.org/10.1080/08351813.2012.646742

Bolden, G. B. (2012). Across languages and cultures: Brokering problems of understanding in conversational repair. Language in Society. https://doi.org/10.1017/S0047404511000923

Canale, M., \& Swain, M. (1980). Theoretical bases of communicative approaches to second language teaching and testing. Applied Linguistics, 1(1), 1-47. https://doi.org/10.1093/applin/I.1.1

Cancino, M. (2015). Assessing learning opportunities in EFL classroom interaction: What can conversation analysis tell us? RELC Journal, 46(2), 115-129. https://doi.org/10.1177/0033688214568109

Cancino, M. (2020). Increasing EFL learner participation through eliciting language: Insights from conversation analysis. Journal of Language and Education, 6(2), 66-80. https://doi.org/10.17323/JLE.2020.10304

Dehé, N. (2015). The intonation of the Icelandic other-initiated repair expressions Ha 'Huh' and Hvað segirðu/ Hvað sagðirðu 'What do/did you say.' Nordic Journal of Linguistics, 38(02), 189-219. https://doi.org/10.1017/ S0332586515000153

Drew, P. (1997). 'Open' class repair initiators in response to sequential sources of troubles in conversation. Journal of Pragmatics, 28, 69-101. https://doi.org/10.1016/S0378-2166(97)89759-7

Emrani, F., \& Hooshmand, M. (2019). A conversation analysis of self-initiated self-repair structures in advanced Iranian EFL learners. International Journal of Language Studies, 13(1), 57-76.

Enfield, N. J., Dingemanse, M., Baranova, J., Blythe, JoePenelope Brown, T., Dirksmeyer, P. D., Simeon Floyd, S., Gipper, R. S., Gi'slado' ttir, Gertie Hoymann, K. H. K., Stephen C. Levinson, Lilla Magyari, E. M., \& Giovanni Rossi, Lila San Roque, \& F. Torreira. (2013). Huh? What? - a first survey in twenty-one languages. In H. Makato, G. Raymond, \& J. Sidnell (Eds.), Conversational Repair and Human Understanding (pp. 343-380). Cambridge University Press. https://doi.org/10.1017/CBO9780511757464.012

Floyd, S., Manrique, E., Rossi, G., \& Torreira, F. (2016). Timing of visual bodily behavior in repair sequences: evidence from three languages. Discourse Processes, 53(3), 175-204. https://doi.org/10.1080/016385 3X.2014.992680

Fotovatnia, Z., \& Dorri, A. (2013). Repair strategies in EFL classroom talk. Theory and Practice in Language Studies, 
3(6), 950-956. https://doi.org/10.4304/tpls.3.6.950-956

Gardner, R. (2013). Conversation analysis in the classroom. In J. Sidnell, \& T. Stivers (Eds.), The Handbook of conversation analysis (pp. 593-611). Wiley- Blackwell. https://doi.org/10.1002/9781118325001.ch1

Golato, A., \& Golato, P. (2015). Reference repair in German and French. Journal of Pragmatics, 87, 218-237.https:// doi.org/10.1016/j.pragma.2014.07.014

Greer, T. (2013). Word search sequences in bilingual interaction: Codeswitching and embodied orientation toward shifting participant constellations. Journal of Pragmatics. https://doi.org/10.1016/j.pragma.2013.08.002

Hayashi, M., \& Kim, S. H. (2015). Turn formats for other-initiated repair and their relation to trouble sources: Some observations from Japanese and Korean conversations. Journal of Pragmatics, 87, 198-217. https://doi. org/10.1016/j.pragma.2013.11.014

Hellermann, J., \& Lee, Y. A. (2014). Members and their competencies: Contributions of ethnomethodological conversation analysis to a multilingual turn in second language acquisition. System, 44, 54-65. https://doi. org/10.1016/j.system.2014.02.006

Hoey, E. M. (2015). Lapses: How people arrive at, and deal with discontinuities in talk. Research on Language and Social Interaction, 48(4), 430-453. https://doi.org/10.1080/08351813.2015.1090116

Hömke, P., Holler, J., \& Levinson, S. C. (2017). Eye blinking as addressee feedback in face-to-face conversation. Research on Language and Social Interaction, 150(1), 1-17. https://doi.org/10.1080/08351813.2017.1262143

Hutchby, I., \& Wooffitt, R. (2002). Conversation analysis : Principles, practices and applications. Polity.

Kasper, G., \& Wagner, J. (2014). Conversation analysis in applied linguistics. Annual Review of Applied Linguistics, 34, 171-212. https://doi.org/10.1017/S0267190514000014

Kaur, J. (2012). Saying it again: Enhancing clarity in English as a lingua franca (ELF) talk through self-repetition. Text and Talk, 32(5), 593-613. https://doi.org/10.1515/text-2012-0028

Khodadady, E., \& Alifathabadi, J. (2012). Repairing conversation and foreign language proficiency. Journal of Language Teaching and Research, 3(4), 736-743. https://doi.org/10.4304/jltr.3.4.736-743

Kushida, S. (2011). Confirming understanding and acknowledging assistance: Managing trouble responsibility in response to understanding check in Japanese talk-in-interaction. Journal of Pragmatics, 43, $2716-$ 2739. https://doi.org/10.1016/j.pragma.2011.04.011

Lázaro-Ibarrola,A., \& Azpilicueta-Martínez, R. (2015). Investigating negotiation of meaning in EFL children with very low levels of proficiency. International Journal of English Studies, 15(1), 1-21. https://doi.org/10.6018/ ijes/2015/1/203751

Lee, E. J. (Esther). (2013). Corrective feedback preferences and learner repair among advanced ESL students. System, 41(2), 217-230. https://doi.org/10.1016/j.system.2013.01.022

Lehti-Eklund, H. (2013). Code-switching to first language in repair - A resource for students' problem solving in a foreign language classroom. International Journal of Bilingualism, 17(2), 132-152. https://doi. org/10.1177/1367006912441416

Lilja, N. (2014). Partial repetitions as other-initiations of repair in second language talk: Re-establishing understanding and doing learning. Journal of Pragmatics, 71, 98-116. https://doi.org/10.1016/j. pragma.2014.07.011

Morgenstern, A., Leroy-Collombel, M., \& Caët, S. (2013). Self- and other-repairs in child-adult interaction at the intersection of pragmatic abilities and language acquisition. Journal of Pragmatics, 56(1), 151-167. https:// doi.org/10.1016/j.pragma.2012.06.017

Mortensen, K. (2016). The body as a resource for other-initiation of repair: Cupping the hand behind the ear. Research on Language and Social Interaction, 49(1), 34-57. https://doi.org/10.1080/08351813.2016.1126450

Nation, I. S. P., \& Newton, J. (2009). Teaching ESL/EFL listening and speaking. In ESL Applied Linguistics Professional Series (vol. 15). Routledge. https://doi.org/10.1016/j.system.2009.11.002

O’Neal, G. (2015). Segmental repair and interactional intelligibility: The relationship between consonant deletion, consonant insertion, and pronunciation intelligibility in English as a Lingua Franca in Japan. Journal of Pragmatics, 85, 125-134. https://doi.org/10.1016/j.pragma.2015.06.013

Osvaldsson, K., Persson-Thunqvist, D., \& Cromdal, J. (2013). Comprehension checks, clarifications, and corrections in an emergency call with a nonnative speaker of Swedish. International Journal of Bilingualism, 17(2), 205-220. https://doi.org/10.1177/1367006912441420

Persson, R. (2015). Registering and repair-initiating repeats in French talk-in-interaction. Discourse Studies, 17(5), 583-608. https://doi.org/10.1177/1461445615590721

Plug, L. (2015). Discourse constraints on prosodic marking in lexical replacement repair. Journal of Pragmatics, 87, 80-104. https://doi.org/10.1016/j.pragma.2015.07.005

Rabab'ah, G. (2013). Strategies of repair in EFL learners' oral discourse. English Language Teaching, 6(6), 123- 


\section{MADAR ALEKSIUS}

131. https://doi.org/10.5539/elt.v6n6p123

Radford, J. (2010). Practices of other-initiated repair in the classrooms of children with specific speech and language difficulties. Applied Linguistics, 31(1), 25-44. https://doi.org/10.1093/applin/amn046

Ryan, J. (2015). Reconstructing miscommunications for the language classroom. ELT Journal, 69(4), 405414. https://doi.org/10.1093/elt/ccv016

Saldert, C., Ferm, U., \& Bloch, S. (2014). Semantic trouble sources and their repair in conversations affected by Parkinson's disease. International Journal of Language and Communication Disorders, 49(6), 710-721. https:// doi.org/10.1111/1460-6984.12105

Sasuga, M., \& Greer, T. (2014). Forward-oriented medium repair in Japanese. English bilingual interaction. Japan Journal of Multilingualism and Multiculturalism, 14, 1-16.

Schegloff, E. (2000). When “others" initiate repair. Applied Linguistics, 21(2), 205-243. https://doi.org/10.1093/ applin/21.2.205

Schegloff, E. A. (2007). Sequence organization in interaction: A primer conversation analysis volume 1. Cambridge University Press.

Schegloff, E. A., Jefferson, G., \& Sacks, H. (1977). The preference for self-correction in the organization of repair in conversation. Language, 53(2), 361-382. https://doi.org/10.2307/413107

Seedhouse, P. (2005). Conversation analysis and language learning. Language Teaching, 38(4), 165-187. https:// doi.org/10.1017/S0261444805003010

Seo, M. S., \& Koshik, I. (2010). A conversation analytic study of gestures that engender repair in ESL conversational tutoring. Journal of Pragmatics, 42(8), 2219-2239. https://doi.org/10.1016/j.pragma.2010.01.021

Sert, O., \& Jacknick, C. M. (2015). Student smiles and the negotiation of epistemics in L2 classrooms. Journal of Pragmatics, 77, 97-112. https://doi.org/10.1016/j.pragma.2015.01.001

Tavakoli, H. (2012). A dictionary of research methodology and statistics in applied linguistics. Rahnama Press.

ten Have, P. (2007). Doing conversation analysis. SAGE Publications.

Tudini, V. (2016). Repair and codeswitching for learning in online intercultural talk. System, 62, 15-25. https:// doi.org/10.1016/j.system.2016.06.011

Walker, G. (2017). Young children's use of laughter as a means of responding to questions. Journal of Pragmatics, 112, 20-32. https://doi.org/10.1016/j.pragma.2017.02.006

Wang, J., \& Wu, J. (2015). Conversation repair in the class with Chinese as foreign language. Theory and Practice in Language Studies, 5(7), 1525-1533. https://doi.org/10.17507/tpls.0507.29

Wong, J., \& Waring, H.Z. (2010). Conversation analysis and second language pedagogy: A guide for ESL/EFL teachers. Routledge. 